Journal of Qualitative Criminal Justice \& Criminology

\title{
Book Review | Women on Ice: Methamphetamine Use among Suburban
}

\section{Women}

Karen McElrath ${ }^{1}$

${ }^{1}$ Fayetteville State University

Published on: Oct 01, 2013

DOI: 10.21428/88de04a1.19e49568

License: Creative Commons Attribution 4.0 International License(CC-BY 4.0) 
Miriam Boeri. Women on Ice: Methamphetamine Use among Suburban Women. Rutgers University Press, 2013; 231 pp.; ISBN: 9780813554594.

Some readers fail to read the preface to a book, eager to step inside the chapters. I began with the preface to Women on Ice and then returned to it after I had read the book in its entirety. The preface provides the reader with a brief but important snapshot of Miriam Boeri as an author and one whose family, like so many others, has experienced addiction. These life events shaped her interest in studying people who experience problems with psychoactive drug use. Moreover, authors who share this kind of "private trouble" help to de-stigmatize drug addiction (see also, the self-disclosure by neuroscientist and author, Carl Hart).

This book consists of eight chapters filled with interesting vignettes that portray the experiences of a heterogeneous sample of women who reside in suburbia. In Chapter 1, we are introduced to Maggie, Mia, and Dee, whose experiences with methamphetamine are similar in some ways, yet with very different outcomes linked to social capital and drug trajectories. The contemporary history of methamphetamine is presented with brief introductory descriptions of Crystal Meth, Crank, and Ice. Boeri notes that methamphetamine epidemics have been linked to particular subcultures; suburban women have largely been neglected in the previous research. This introductory chapter also includes a discussion of prior research findings as they relate to gender and methamphetamine as well as to gender and structural violence.

The methodology is described in Chapter 2, with additional detail (e.g., analytical strategy) provided in Appendix A. The writing style in this chapter is generally devoid of heavy methodological jargon and will appeal to lay readers, students, as well as academic scholars. The ethnographic work was guided by intense recruitment strategies that resulted in a sample of women $(\mathrm{N}=65)$ who were quite diverse in terms of age and social class. Fifty-eight of these suburban women were white non-Hispanic. We learn at one point that dealers were White and the 7 other respondents (African-American, Latina, and Native American) were initiated into methamphetamine by Whites.

In Chapter 3 (The Gendered Drug Career), Boeir discusses her typology of the phases of drug use. Drawing from life course, social control, and self-control perspectives, the typology includes nine stages: 1. controlled occasional user; 2. weekend warrior; 3. habitué; 4. marginal user; 5 . problem addict; 6. dealer/runner; 7. hustler/sex worker; 8. junkie; and 9. relapsing addict/junkie. She notes that the addict label was used by respondents and was not the term that she preferred. Consistent with life course theory, there are "transitions and turning points at every phase of the drug career" (p. 50). With its focus on gender, this work and the detail in Appendix B adds greatly to the literature on drug careers. Boeri describes another organizing pattern by situating respondents into three categories: 1) 
suburban youth culture, 2) suburban working and middle class, and 3) suburban poor. The implications of women's social class and age are powerful and are comprehensively illustrated in several vignettes. Readers will empathize in particular with the suburban poor who "remained outside the radar of the social services" and resided in places described as "suburban enclaves of poverty" ( $p$. 23).

Gendered lives are the focus of Chapter 4. Boeri emphasizes the importance of social capital and how it influences transitioning from conventional to unconventional roles. We learn how methamphetamine use affected family relations and women's personal health. Boeri explores the meaning of motherhood and the loss of this conventional role as the mechanisms of social control shape the women's lives. We learn about the despair among the women, and some of the narratives and vignettes are difficult to read. In this chapter and elsewhere in the book, we learn about the males in the women's lives; a few males are helpful, others are exploitative, controlling, and bail out when problems arise.

Chapters 5 and 6 address gendered risks that pertain to health and violence. Using a series of vignettes, Boeri illustrates respondents' adverse health conditions (e.g., kidney damage, gall bladder disease, extensive tooth decay, depression, bipolar illness). Some respondents moved from methamphetamine to pain pills and methadone or had combined these substances, consistent with simultaneous polydrug use described in studies of other types of drug use. Readers from some European countries might be surprised to learn that a large number of clients in the US are required to pay for daily methadone doses (in this instance, \$12 per day), which reflects the dominant ideology of drug treatment in the US. The research on violence and crime shows the continuation of violence that sometimes commenced during childhood. This finding has been documented in several other studies of women who use drugs, including research conducted in other cultures and with women whose drugs of choice are other than methamphetamine.

Chapter 7 focuses on treatment, recovery and relapse to which Boeri refers to as a revolving door. Here, we are presented with the devastating implications of the War on Drugs. Boeri notes that food stamps are unavailable to those with a felony drug conviction (but not other felony convictions). How can it be that a democratic society restricts access to basic human needs-food and shelter-based on individuals' connections to psychoactive substances? Boeri describes women's experiences with drug courts and notes that some respondents perceived that they had benefited from these interventions. Advocates of the drug court model might capitalize on these findings. Boeri suggests that "social recovery" (as opposed to abstinence) should be the first goal on the slow road to recovery. Social recovery includes the "skills, resources and networks needed that enhance people's ability to live in society without resorting to problematic alcohol or drug use" (p. 157).

The final chapter addresses policy implications, and rich narratives portray women transitioning from the security of private residences to the vulnerability associated with homelessness. Boeri offers six 
interesting proposals for change: 1. harm reduction (e.g., mobile services to reach the suburban poor); 2. social recovery (she uses vignettes to illustrate how social recovery might be accomplished); 3 . treatment on demand; 4 . housing first that advocates low threshold and high tolerance housing (she incorporates work on surveillance and social control mechanisms that regulate and monitor "social deviants"); 5. restorative and transformative justice; and 6. female initiated programs.

Throughout the book, I observed that women's behaviors were often influenced by structural barriers and institutionalized stigma whereby the drug user label was nearly impossible to shake, even when women demonstrated progress toward recovery. It was as if the system resisted the very notion of recovery and the challenges faced by people in recovery. The structural barriers that reduced the likelihood of recovery included the limited availability of drug treatment and the irony that jails and prisons provided the best opportunity for treatment for most of the respondents. Twelve-step programs were used because they were economically viable and anonymous - so important to many of these women who wished to avoid the stigma of the public gaze. Hospital emergency rooms were used in hopes of availing of detox programs, hardly a treatment option, although an important step in the treatment process. Structural barriers included the high threshold entrance criteria for accommodation in homeless shelters (where identification cards are hot commodities) as well as the drug testing that has made its ugly way into homeless shelters and used as a tool of exclusion. I pondered the contradiction between exclusionary practices in places referred to as shelters and wondered why private health insurance provided funds for such limited time in drug treatment, regulations that are inconsistent with what the scientific evidence has found in terms of the benefits of long stays in treatment. To me, Women on Ice is a damning indictment of the US system and how it responds to people experiencing problems with drug use.

Research textbooks generally warn us to remain objective. Ethnography makes this impossible when researchers are confronted with human despair. Boeri takes a side, an empathetic one, and it is refreshing to see how she does it, as she steps out of the research role in an attempt to address the void in social services. Boeri treats respondents to meals, assists them in locating employment and accommodation, provides the warm coats, and drives respondents to appointments. Her commitment to the respondents has been guided by not only the ethnographic pursuit but because she cared. In one section, Boeri describes how she and two staff members phoned more than 20 services in an attempt to find accommodation for one woman respondent: "The evidence we collected that week supported what the women had told us: They [services] never call back" (p. 160).

I have minor quibbles with the material in this book. First, the theoretical emphasis on social roles is fascinating, but I would have preferred more exploration into the structural barriers that contribute to changes across roles and trajectories. To me, respondents' narratives provide glaring evidence of institutionalized stigma that seems to reinforce a drug user identity. Boeri is very critical of these 
social control mechanisms but does not really link the damages in the collective. Still, researchers have different views of the social world and the data that is produced from it. Second, Boeri notes that mixed-method strategies "are relatively new" (p. 187). I agree that mixed-method strategies have gained momentum; however, I am reminded of W. E. B. Du Bois' mixed-method approach in his urban study that he conducted over 100 years ago and was reviewed recently in this journal. In summary, Women on Ice contributes to our understanding of women and drug use. It highlights both the social construction of the meth panic and the despair that methamphetamine use can create. It notes the importance of social class and age among women whose trajectories are altered. The book is well worth the read.

\section{References}

Hart, C. (2013). High price: A neuroscientist's journey of self-discovery that challenges everything you know about drugs and society. New York, NY: Harper. 